\title{
Hyperextension trauma to the elbow: radiological and ultrasonographic evaluation in handball goalkeepers
}

\author{
N Popovic, R Lemaire
}

Br J Sports Med 2002;36:452-456

\begin{abstract}
Objective: To detect elbow lesions produced by hyperextension in 30 elite handball goalkeepers.
Methods: Conventional radiographs, stress radiographs, and ultrasound examination of both elbows were used. As a control group, 30 male volunteers from the general population within the same age group with no history of elbow injury were used. Results: Radiographic findings in the goalkeepers were osteophyte formation in 67\%, loose bodies in $5.5 \%$, and periarticular calcification in 5.5\%. Significantly greater differences in medial joint space opening between stressed and unstressed elbows were measured in both elbows than in the control group. Ultrasonographic findings showed thickening of the medial collateral ligament in $50 \%$, thickening of the tricipital tendon in $11 \%$, and signs of ulnar neuritis in $22 \%$. An intra-articular effusion was found in $66 \%$ and small loose bodies in $33 \%$. No significant differences were found between the dominant and non-dominant elbows at radiological and ultrasound examination. The findings in the control group were normal.

Conclusions: The findings support the theory that repetitive hyperextension trauma to the elbow in
\end{abstract}

See end of article for authors' affiliations handball goalkeepers results in pathological changes.

N Popovic, Orthopaedic

Department, University

Hospital, Sart-Tilman,

B-4000 Liège, Belgium

chirortho@ulg.ac.be

Accepted 14 May 2002

S ports injuries involving the structures of the elbow occur in distinct patterns. ${ }^{1}$ In the past, most studies of elbow injuries have been in athletes in throwing or other overhead sports. ${ }^{2-4}$ The injuries are usually chronic in nature and the result of repetitive overload of medial structures of the elbow. ${ }^{5-7}$

Impact injuries of the elbow caused by the ball hitting a fully extended distal part of the forearm in handball goalkeepers have been well described by Tyrdal et al. ${ }^{8}$ According to their epidemiological study, $75 \%$ of the goalkeepers in European team handball had experienced elbow problems during their career. Almost all (95\%) had been caused by repetitive hyperextension trauma when blocking shots. ${ }^{90}$ The symptoms usually started acutely, but were chronic in nature, with intermittent periods of elbow pain as the chief complaint. Anatomical lesions included anterior capsule rupture, L shaped rupture of the flexor-pronator origin with elongation of the anterior part of the medial collateral ligament (MCL), occasional incomplete rupture of the lateral collateral ligament, and detachment of small fragments of cartilage near the posterior edge of the olecranon. ${ }^{11}$ One or more of these lesions may be responsible for the symptoms in handball goalkeeper's elbow.

Before an effective treatment plan can be developed for an athlete with this condition, a diagnosis must be secured. Many authors have reported the use of various imaging techniques to detect pathological changes in the elbow related to the throwing mechanism. ${ }^{512-15}$ The purpose of this study was to detect by conventional radiography, stress radiography, and ultrasound (US) examination, lesions generated in the handball goalkeeper's elbow by the mechanism of hyperextension. In addition, we compared these findings with those found in a general population of the same age group, who do not practice sports involving the elbow.

\section{MATERIALS AND METHODS}

The study included 30 male handball goalkeepers with no clinical evidence of valgus elbow instability. Their mean age was 26.7 years (range 18-38). The players had a mean athletic experience of 15 years (range 8-18).
The control group comprised 30 male volunteers from the general population with no history of elbow injury. Their mean age was 26.4 years (range $21-37$ ). Twenty five of them did not practice any sports involving the elbow, and five occasionally played sports involving the elbow but for less than one to two hours a month.

All subjects gave informed consent for the following examination of the elbows: plain radiographs, stress radiographs, and US. The study received approval from the ethics committee of our university hospital.

All goalkeepers had an orthopaedic examination of both elbows, consisting of documentation of active range of motion, MCL integrity, and nature and location of elbow symptoms. Active range of motion for elbow extension and flexion was measured using a standard universal goniometer.

Comparative plain films of both elbows were obtained in anteroposterior and lateral projections. The anteroposterior projection was obtained during maximum extension of the elbow, and the lateral projection was obtained with the elbow flexed to a right angle. Evaluation was based on chronic diffuse and localised radiological manifestations of skeletal stress at the elbow.

Joint effusion, loose bodies, osteophytes, traction spur formation, and calcifications of the elbow were evaluated.

Stress radiographs of both elbows were obtained using a Telos GA-II E stress device (Telos, Weiterstadt, Germany), which provided a consistent extremity position and application of valgus stress to the elbow. The upper arm was externally rotated and abducted such that the hand and the wrist were at shoulder level. The elbow was flexed $30^{\circ}$ to unlock the olecranon from its bony fossa. Elbow flexion was verified using a standard universal goniometer. The forearm was positioned in full supination. This was accomplished by having the patients grasp a handle on the Telos device. The force applied to the lateral side of the elbow was $150 \mathrm{~N}$. Anteroposterior radiographs of both elbows were obtained

Abbreviations: MCL, medial collateral ligament; US, ultrasound 
Table 1 Stress radiography values and statistical analysis of medial elbow laxity between elbows (dominant and non-dominant sides) in/and between the two different groups (goalkeepers and controls)

\begin{tabular}{|c|c|c|c|c|c|c|}
\hline \multirow[b]{2}{*}{ Test conditions } & \multicolumn{3}{|l|}{ Dominant side } & \multicolumn{3}{|c|}{ Non-dominant side } \\
\hline & Goalkeepers & Controls & p Value & Goalkeepers & Controls & $\mathrm{p}$ Value \\
\hline Joint width without stress (d0) & $3.52(0.5)$ & $3.51(0.5)$ & 0.48 & $3.53(0.6)$ & 3.5210 .50 & 0.49 \\
\hline Joint width with valgus stress (d15) & $4.70(0.8)$ & $4.46(0.9)$ & 0.13 & $4.69(0.9)$ & $4.44(0.8)$ & 0.13 \\
\hline Differences (d15-d0) & $1.18(0.9)$ & $0.95(0.5)$ & 0.11 & $1.16(0.5)$ & $0.92(0.6)$ & 0.09 \\
\hline $\begin{array}{l}\text { Comparison of dominant with } \\
\text { non-dominant side }\end{array}$ & \multicolumn{3}{|l|}{ Goalkeepers } & \multicolumn{3}{|l|}{ Controls } \\
\hline Joint width without stress (d0) & \multirow{3}{*}{\multicolumn{3}{|c|}{$\begin{array}{l}p=0.47 \\
p=0.48 \\
p=0.46\end{array}$}} & \multirow{3}{*}{\multicolumn{3}{|c|}{$\begin{array}{l}p=0.46 \\
p=0.46 \\
p=0.40\end{array}$}} \\
\hline Joint width with valgus stress (d15) & & & & & & \\
\hline \multirow[t]{3}{*}{ Differences $(\mathrm{d} 15-\mathrm{d} 0)$} & & & & & & \\
\hline & \multicolumn{3}{|l|}{ Goalkeepers } & \multicolumn{3}{|l|}{ Controls } \\
\hline & Dominant side & \multicolumn{2}{|c|}{ Non-dominant side } & Dominant side & \multicolumn{2}{|c|}{ Non-dominant side } \\
\hline Comparison between $\mathrm{d} 0$ and $\mathrm{d} 15$ values & $\mathrm{p}=2.59 \mathrm{E}-08$ (SD) & \multicolumn{2}{|c|}{$\mathrm{p}=5.12 \mathrm{E}-13(\mathrm{SD})$} & $\mathrm{p}=2.96 \mathrm{E}-11$ (SD) & \multicolumn{2}{|c|}{$\mathrm{p}=2.52 \mathrm{E}-10(\mathrm{SD})$} \\
\hline
\end{tabular}

with 0 and $150 \mathrm{~N}$ of valgus force. The medial joint space, the distance between the trochlea of the humerus and the ulnar coronoid process, before and after valgus stress, were measured. Our radiographic system used phosphorus crystal plates and an analogue to digital converter system for development. This allowed zooming of the digital image on a screen and provided more accurate measurements.

A bilateral comparative US examination of the elbow was performed with a $7.5 \mathrm{MHz}$ linear array probe using high definition US equipment (Performa; Dornier, Munich, Germany). Anterior (transverse, longitudinal), coronal (medial, lateral), and posterior (transverse, longitudinal) bilateral comparative scans were performed.

The anterior transverse and longitudinal scans (elbow extended, forearm supinated) allowed study of the coronoid fossa (effusion and loose bodies), the trochlear and capitellar cartilage, and the anterior articular capsule thickness.

The coronal medial scans (elbow extended, forearm supinated) allowed the study of US appearance and the thickness of the common flexor-pronator muscle group at its origin, the thickness and possible US modifications of the anterior bundle of the ulnar collateral ligament, and the thickness and echogenicity of the ulnar nerve.

The lateral coronal scans (elbow extended, forearm semipronated) allowed the study of the thickness of the annular ligament, the lateral capsule, and the proximal extensor tendons.

Posterior transverse and longitudinal scans (elbow flexed, palm of the hand against the table) allowed the study of the thickness and US appearance of the posterior cartilage, thickness and US aspects of the tricipital tendon, and effusion and loose bodies in the olecranon fossa.

On US examination of the elbow, the common flexorpronator, extensor, and triceps tendons are seen as hyperechoic fibrillar structures. The articular cartilage is seen as a thin hypoechoic line between the fat pad and the bone. Effusion is seen as anechoic fluid. The MCL is visualised as a linear hyperechoic structure. Echography shows intra-articular bodies as focal echogenic reflectors separate from cortical bone. The thickness of the MCL, flexor-pronator, extensor and triceps tendons as well as the ulnar nerve and the articular cartilage of the elbow was measured. Homogeneity of the tendons and ligaments was evaluated. Articular recesses were scanned for fluid and loose bodies.

\section{Statistical analysis}

An unpaired Student's $t$ test was used to test differences in medial elbow laxity between elbows in the two different groups (goalkeepers and controls) with significance set at the 0.05 level.

A paired Student's $t$ test was used to test differences in the thickness of the MCL, flexor-pronator, extensor, and triceps tendons as well as the ulnar nerve and joint cartilage thickness. An intraclass correlation coefficient was used to determine test-retest reliability.

\section{RESULTS}

Upon clinical examination, 25 goalkeepers complained of chronic elbow pain: only five were free of elbow pain. The pain was intermittent in 17, and in eight with longer athletic careers, the elbow pain was constant. The pain affected the ulnar side $(55 \%)$, the radial side $(20 \%)$, the front $(15 \%)$ or the back $(10 \%)$ of the elbow. No players complained of elbow clicking or locking. The goniometric measurements of the range of motion in the 30 goalkeepers showed a mean (SD) decrease in elbow extension of $-3.52(0.86)^{\circ}$ on the dominant side and $-3.28(0.79)^{\circ}$ on the non-dominant side. Minimal non-significant limitation in elbow flexion was noted for the dominant extremity compared with the non-dominant extremity $\left(141.28(3.42)^{\circ} \mathrm{v} 142.90(2.94)^{\circ}\right)$.

Radiographic examination of the goalkeepers found that the main abnormality was osteophyte formation, in $67 \%$ of the cases. The osteophytes were usually located at the olecranon process and were most prevalent in the most experienced players. Loose bodies were visualised in $5.5 \%$, and periarticular calcifications were also seen in $5.5 \%$ of the players. We found no radiological signs of joint effusion and no significant differences between the dominant and non-dominant extremities. Radiological findings in the control group were normal.

Table 1 shows the findings of bilateral stress examination of the two groups. The change in joint opening with valgus stress (d15-d0) was significant for both groups in the dominant and non-dominant elbows $(\mathrm{p}<0.0001)$. The values taken from the radiographs of the dominant and the non-dominant elbows in the goalkeepers (d15-d0) did not identify any significant difference between extremities $(p=0.46)$. There was no significant difference in the amount of valgus stress opening between the goalkeepers and controls.

Table 2 shows the results of measurements of the thickness of the flexor-pronator, extensor, and tricipital tendons, MCL, annular ligament, and ulnar nerve by US in both elbows in the goalkeepers and controls.

The MCL was thickened in $50 \%$ of the goalkeepers, and this thickening was distal in $39 \%$ and diffuse in $11 \%$. No US signs 


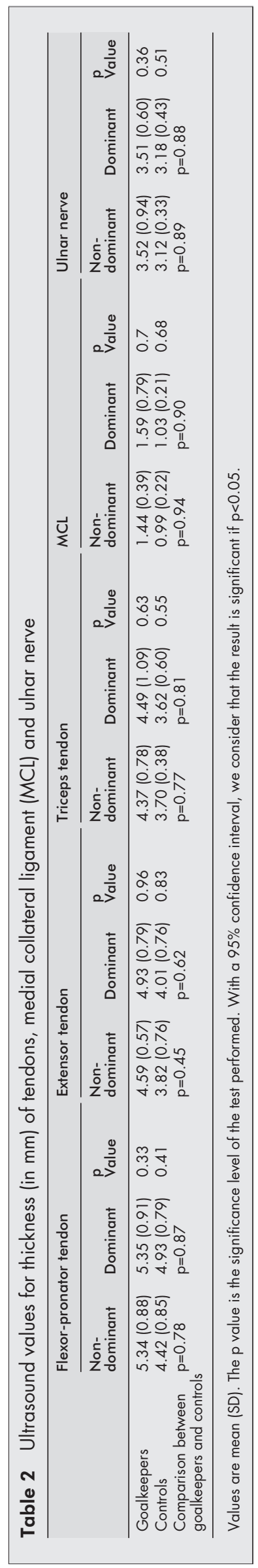

of rupture of the MCL were observed in this group. Thickening of the tricipital tendon was observed in $11 \%$, and fissures in $5.5 \%$ of the goalkeepers. US signs of ulnar neuritis were found in $22 \%$ of the goalkeepers.

Table 3 gives the results of measurements of the thickness of the cartilage and anterior capsule by US in both elbows in the two groups. The joint cartilage was irregular in $18 \%$ of the athletes, particularly the olecranon cartilage. This was found especially in goalkeepers with longer athletic careers. The anterior articular capsule was thickened in most goalkeepers compared with the control group.

An intra-articular effusion was found in $66 \%$ of the players. The effusion was usually localised in the annular recess (44\%) followed in frequency by the coronoid fossa (39\%) and the olecranon fossa $(33 \%)$. Small loose bodies in the articular recess were found in 33\% of the goalkeepers, particularly those with longer athletic careers.

No significant differences between dominant and nondominant extremities were found in the goalkeepers on echographic examination.

In the control group, no joint effusions and loose bodies were found on US examination, and no signs of ulnar neuritis were detected. The tendons of the flexor, extensor, and triceps muscles and the MCL all had a normal US appearance. The anterior articular capsule and the cartilage were normal.

\section{DISCUSSION}

This study confirms that pain in the elbow is a common problem for handball goalkeepers at all levels of participation. Constant moderate medial pain was particularly found in goalkeepers with longer athletic careers.

The mechanism of injury appears to be repetitive hyperextension trauma caused by the ball hitting a fully extended distal forearm with considerable energy as noted by Tyrdal et al. ${ }^{8}$

To our knowledge, no studies on imaging of the elbow lesions caused by the mechanism of hyperextension in handball goalkeepers have been reported. The radiological findings in this study clearly show differences between the goalkeepers and the non-sporting controls.

Hypertrophic osteophytes and traction spurs were observed in goalkeepers on plain radiographs. They result from repetitive excessive extension forces generated in the elbow at the moment of shot blocking. This repeated impaction of the posteromedial olecranon in the olecranon fossa leads to chondromalacia and subsequent hypertrophic spur and osteophyte formation. We found no radiological manifestation of elbow stress in the controls.

Elbow valgus stress radiography has been recommended as an aid in the diagnosis of valgus instability in throwing athletes. ${ }^{16}{ }^{17}$ The use of $15 \mathrm{~N}$ of valgus stress was recommended by Rijke et al ${ }_{1}^{16}$ who found medial joint opening with application of this level of stress in cadaveric limbs.

Stress radiographs using a Telos device with $150 \mathrm{~N}$ valgus stress in the control group did not show joint widening of more than $0.5 \mathrm{~mm}$ between extremities. The findings in the goalkeepers confirm medial joint opening in some players, which probably reflects some MCL laxity in these athletes. This abnormal amount of laxity may be the consequence of repetitive hyperextension trauma of the elbow. We did not find any significant difference in laxity between the dominant and non-dominant extremities in the goalkeepers or between the group of goalkeepers and the control group. Our results agree with findings of Singh et $a l^{19}$ that no numerical value can confidently determine the pathological status of the ulnar collateral ligament of the elbow when using stress radiography.

US examination confirmed $67 \%$ with joint effusion, which we did not detect on plain films. US showed the precise location of the effusion. It is usually believed that the effusion is most common in the olecranon fossa followed by the coronoid fossa and annular recess. ${ }^{5}{ }^{13}$ In these handball goalkeepers, the 


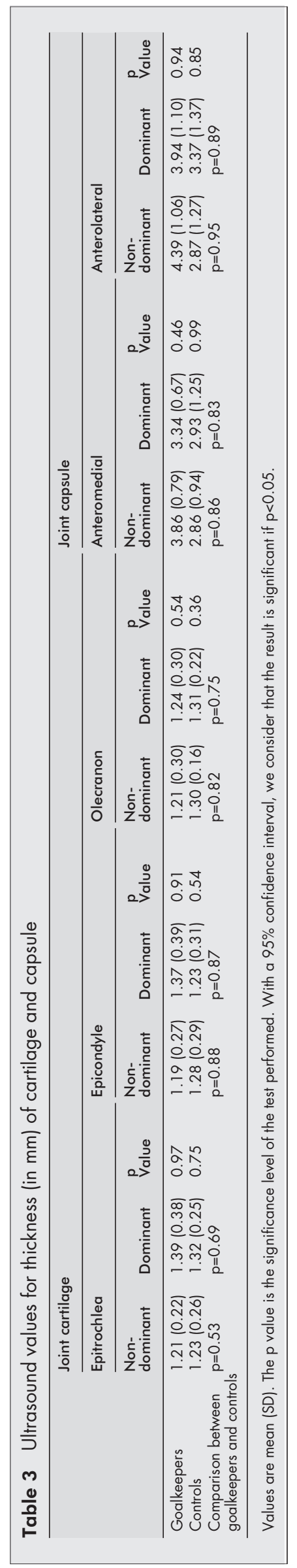

Take home message

Hyperextension trauma of the elbow in handball goalkeepers provokes pathological changes, as confirmed by radiological and ultrasonographic evaluation.

effusion was more common in the annular recess $(44 \%)$, followed by the coronoid fossa $(39 \%)$, and finally the olecranon fossa $(33 \%)$.

US examination showed thickening of the MCL, flexorpronator tendon, and triceps tendon of both elbows in goalkeepers compared with the control group. We cannot confirm, but we can argue, that repetitive hyperextension trauma of the elbow in these athletes results in microrupture of soft tissue around the elbow as described by Tyrdal et al. ${ }^{11}$ The imperfect healing process of soft tissue (MCL, flexor-pronator tendon, extensor tendon, and triceps tendon) results in the thickening of these structures seen on US examination.

The thickening of the ulnar nerve seen on US examination may be the result of pathological and physiological responses to repetitive impact trauma of the elbow. These changes could be attributed to nerve traction and irritation resulting from direct overload of the elbow caused by the ball hitting a fully extended forearm. We can argue that a cumulative effect of repeated nerve traction in these athletes may produce nerve fibrosis and ischaemia with further increases in intraneural pressure and the clinical symptoms of ulnar neuritis found particularly in goalkeepers with longer athletic careers.

From the findings of this study, it seems that repetitive hyperextension stress of the elbow in handball goalkeepers provokes small pathological changes (confirmed by US examination) and increased medial laxity of the elbow (seen on stress radiography). This laxity can ultimately lead to chronic repetitive injuries of the elbow especially in goalkeepers with poor dynamic muscular stabilisation of the elbow. However, athletes who participate in other sports that involve similar impact injuries of the elbow, such as soccer goalkeepers, volleyball players, and wrestlers, can be likewise affected.

Understanding the anatomy, biomechanics, and pathophysiology of the functional elbow is essential to the recognition, diagnosis, and treatment of these specific elbow injuries.

\section{Authors' affiliations}

N Popovic, R Lemaire, Orthopaedic Department, University Hospital, Sart-Tilman, B-4000 Liège, Belgium

\section{REFERENCES}

1 Safran MR. Elbow injuries in athletes: a review. Clin Orthop 1995;310:257-77.

2 Jobe FW, Nuber G. Throwing injuries to the elbow. Clin Sports Med 1986;5:621-36.

3 Johnston J, Plancher KD, Hawkins RJ. Elbow injuries to the throwing athlete. Clin Sports Med 1996;15:307-29.

4 Wilson FD, Andrews JR, Blackburn TA, et al. Valgus extension overload in the pitching elbow. Am J Sports Med 1983;11:83-8.

5 Mirowitz SA, London SL. Ulnar collateral ligament injury in the baseball pitchers: MR imaging evaluation. Radiology 1992;185:573-6.

6 Morrey BF, An KN. Functional anatomy of the ligaments of the elbow. Clin Orthop 1985;201:84-90.

7 Nirschl RP. Elbow tendinosis, tennis elbow. Clin Sport Med 1992;11:851-70.

8 Tyrdal S, Bahr R. High prevalence of elbow problems among goalkeepers in European team handball: "handball goalie's elbow". Scand J Med Sci Sports 1996;6:297-302.

9 Popovic N. Sportske povrede u rukometu. Sportska Knjiga Beograd 1986:92-101.

10 Seil R, Rupp S, Tempelhof S, et al. Sports injuries in team handball: a one-year prospective study of sixteen men's senior teams of a superior non professional level. Am J Sports Med 1998;26:681-7.

11 Tyrdal S, Olsen BS. Hyperextension of the elbow joint: pathoanatomy and kinematics of ligament injuries. J Shoulder Elbow Surg 1998; 7:272-83. 
12 Gore RM, Rogers LF, Bowerman J, et al. Osseous manifestations of elbow stress associated with sports activities. AUR Am J Roentgenol 1980; 134:971-7.

13 Miller TT. Imaging of elbow disorders. Orthop Clin North Am 1999;30:21-7.

14 Popovic N, Ferrara MA, Daenen B, et al. Imaging overuse injury of the elbow in professional team handball players: a bilateral comparison using plain films, stress radiography, ultrasound, and magnetic resonance imaging. Int J Sports Med 2001;22:60-7.

15 Sonin $\mathbf{A H}$, Fitzgerald SW. MR imaging of sports injuries in the adult elbow: a tailored approach. AJR Am J Roentgenol 1996;167:325-31.
16 Ellenbecker TS, Mattalino AJ, Elam EA, et al. Medial elbow joint laxity in professional baseball pitchers. A bilateral comparison using stress radiography. Am J Sports Med 1998;26:420-4.

17 Lee GA, Katz SD, Lazarus MD. Elbow valgus stress radiography in an uninjured population. Am J Sports Med 1998;26:425-8.

18 Rijke AM, Goitz HT, McCue FC, et al. Stress radiography of the medial elbow ligaments. Radiology 1994;191:213-16.

19 Singh $\mathbf{H}$, Osbahr DC, Wickham $M Q$, et al. Valgus laxity of the ulnar collateral ligament of the elbow in collegiate athletes. Am J Sports Med 2001;29:558-62.

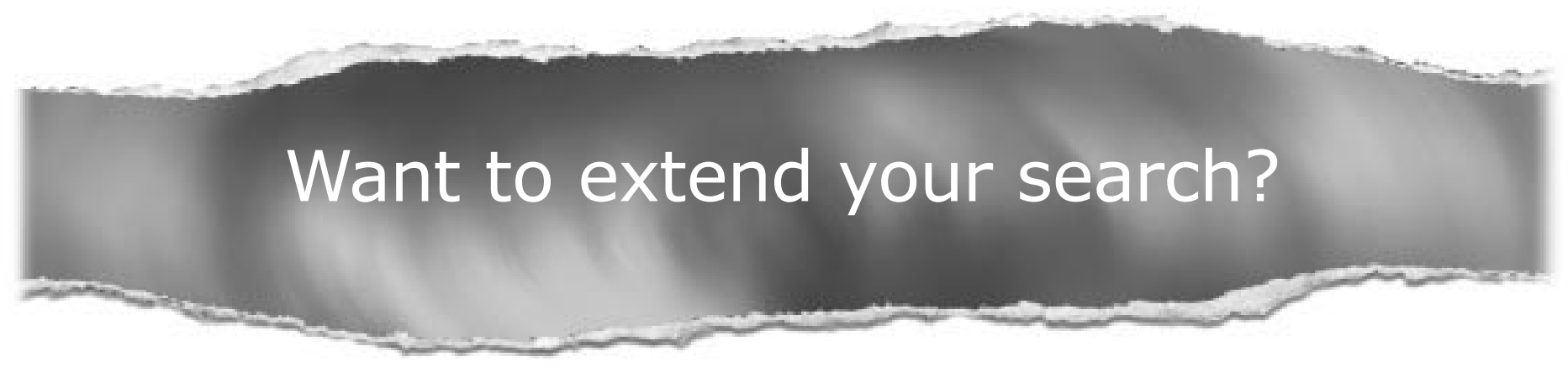

\section{Cross journal searching}

If you can't find what you are looking for in the British Journal of Sports Medicine you can extend your search across many of the more than 200 journals available for selection. You can restrict your search to specific subject areas (eg, clinical medicine, basic research), or select specific journals, or search all available titles.

\section{www.bjsportmed.com}

